\title{
Effects of treatment on free radicals in patients with pulmonary tuberculosis in South Western Nigeria.
}

\author{
Wasiu Olalekan Adebimpe ${ }^{1}$, Ayodeji Oluwaseun Faremi², Sulaiman Adebayo Nassar ${ }^{3}$
}

\begin{abstract}
1. Department of Community Medicine, College of Health Sciences, Osun State University Osogbo, Osun State. Nigeria

2. Central Laboratory Unit, Osun State Hospital Management Board, Osogbo, Osun State. Nigeria

3. Biomedical Sciences Department, Ladoke Akintola University of Technology Ogbomosho.
\end{abstract}

\begin{abstract}
Background: Formation of Malondialdehyde (MDA), a free radical, in Tuberculosis patients does occur when Tubercule bacilli induces reactive oxygen species as a result of phagocytic respiratory burst.

Objectives: This study evaluated the effect of treatment on plasma level of Malondialdehyde among patients infected with Mycobacterium Tuberculosis in Osogbo South Western Nigeria.

Methodology: Descriptive cross sectional study among 110 patients, grouped into four categories (three TB patient categories and controls). All patients were screened for presence or absence of Mycobacterium tuberculosis in their sputum and HIV $1 \& 2$ in their blood using standard techniques. The level of free radical (Malondialdehyde, MDA) was determined by Thiobabituric acid reacting method. Data was analyzed using the SPSS software version 17.0

Results: Serum Malondialdehyde (MDA) levels were significantly lower in TB patients on drugs (TBD) compared with the new cases on treatment $(\mathrm{NCT}) \cdot(0.17+0.88 \mathrm{~mol} / \mathrm{L} \mathrm{Vs} 0.27+0.08 \mathrm{~mol} / \mathrm{L}, \mathrm{p}<0.05)$. Varying degrees of correlations were also found between free radicals and electrolytes.

Conclusion: Reduced serum MDA levels in TBD suggested a reduction in the levels of free radical injury once treatment was commenced. Therefore serum free radical may be an index of monitoring response to treatment in tuberculosis management.

Keywords: Free radicals, malondialdehyde (MDA), mycobacterium tuberculosis, reactive oxygen species, tubercule bacilli, electrolytes.

DOI: http://dx.doi.org/10.4314/ahs.v15i4.26

Cite as: Adebimpe WO, Faremi AO, Nassar SA. Effects of treatment on free radicals in patients with pulmonary tuberculosis in South Western Nigeria. Afri Health Sci. 2015;15(4):1256-61. bttp:/ / dx.doi.org/10.4314/ahs.v15i4.26
\end{abstract}

\section{Introduction}

Tuberculosis (TB) is a re-emerging disease which infects about one-third of the world's current population, with new infections occurring at a rate of one per second. ${ }^{1,2}$ $\mathrm{TB}$ is one of the few diseases for which specific control targets have been set in the Millennium Development Goals. It has been recognized to be associated with a degree of compromise of the immune system, particu-

\footnotetext{
Correspondencing author:

Wasiu Olalekan Adebimpe,

Department of Community Medicine,

College of Health Sciences,

Osun State University Osogbo

PMB 4494 Osogbo, Nigeria

Tel: +2348033712662

Email: lekanadebimpe@gmail.com/

lekanadebimpe@yahoo.com
}

larly failing cytokine responses and overproduction of IL-10 and TGFB. ${ }^{3}$ This is coupled with the involvement of different $\mathrm{T}$ - lymphocytes in immune response against M. tuberculosis, ${ }^{4}$ but production of interferon-gamma (IFN-gamma) by $\mathrm{T}$ cells seems to be fundamental for disease control. ${ }^{5}$

The stimulation of the immune system is caused by an increase in free radical production as a result of increase in phagocytosis. Antioxidants neutralize the free radicals and protect the body from the damaging effects of these free radicals. Mycobacteria can induce reactive oxygen species (ROS) production by activating phagocytes. Although this is an important part of the host defense against Mycobacteria, enhanced ROS generation may promote tissue injury and inflammation. This may further contribute to immune-suppression particularly in those with impaired antioxidant capacity, such as in HIV infected patients. ${ }^{6}$ 
The functional changes in hyper-activated macrophages manifest themselves in their ability to destroy the intracellular micro-organism (Tubercle bacilli). Whenever phagocytosis by activated macrophages fails, hydrogen peroxide $\left(\mathrm{H}_{2} \mathrm{O}_{2}\right)$ is released. This Hydrogen peroxide $\left(\mathrm{H}_{2} \mathrm{O}_{2}\right)$ is released continually by the macrophages with a resultant high free radical load in pulmonary TB clients. ${ }^{7}$ Furthermore, during pulmonary inflammation, increased amounts of ROS and reactive nitrogen intermediates (RNI) are produced as a consequence of phagocytic respiratory burst.

TB is the most common opportunistic infection and the single most common cause of death among HIV infected people in Africa today. ${ }^{8}$ Latent TB infection has been known to revert to active TB following new infection in HIV infected people. TB has been shown to accelerate the progression of HIV disease. These epidemiologic relationships between TB and HIV, and the high prevalence of these diseases in sub-Saharan Africa and indeed Nigeria make studying TB and HIV infected populations in this region of the world important. The malnutrition which is commonly present in patients with tuberculosis can add to the impaired antioxidant capacity in these patients.

This study determined the plasma levels of Malondialdehyde; a product in patients with pulmonary tuberculosis, those with HIV co-infection, and those on treatment. Comparing free radicals level in controls and various categories of TB patients would go a long way in addressing challenges connected with some of the associated electrolyte imbalance from sources such as diarrhea, vomiting and excessive sweating. The overall objective of this study was to determine the effect of treatment on free radical levels in patients with pulmonary tuberculosis.

\section{Methods}

Study location: This study was conducted in Osogbo, an ancient city of approximately 625,000 people based on the last Nigerian census data. ${ }^{9}$ It is located in the heart of SouthWestern Nigerian's Yoruba speaking people and covers about $300 \mathrm{sq} \mathrm{Km}^{2}$. Osogbo with two local governments is served by a secondary, a tertiary and numerous Primary Health Care facilities. There is a non-governmental organization (Damien Foundation) working in the area of TB and HIV in the city. The prevalence of $\mathrm{TB}$ in the city is not readily available; HIV prevalence in the city was $2.9 \%$, which is a bit lower than the national average of $4.1 \% .^{10}$
Study design: This was a hospital-based cross-sectional study among various categories of TB infected patents.

Study population: There were 4 categories of patients recruited from four TB management centers in Osogbo namely Sabo Primary Health Centre, Oke-Baale Primary Health Centre, Osun State University Teaching Hospital,Asubiaro and Ladoke Akintola University of Technology Teaching Hospital, Osogbo. The categories were;

(a) Group 1:50 normal patients without TB or HIV in the sex ratio of $1: 1$

(b) Group 2: 20 new positive cases of Mycobacterium tuberculosis patients without HIV in the ratio of male/ female of 2:1

(c) Group 3: 20 new positive cases of tuberculosis co-infected with HIV in a sex ratio of $1: 1$

(d) Group 4: 20 positive cases of Mycobacterium tuberculosis patients on anti tuberculous drugs consisting of 11 males and 09 females.

Ethical approval: The study received approval of the Research Ethical Review Committee of LAUTECH Teaching Hospital Osogbo, and the permission of the management of the different health facilities. Written informed consent was sought and obtained from each patient after the study had been explained to them.

Sampling procedure: A total of one hundred and ten patients participated in this study. Every new case was screened for Mycobacterium tuberculosis in their sputum using Zielh-Neelsen modified technique. The presence or absence of HIV in their blood was detected by using the national algorithm for the diagnosis of HIV (Determine-Unigold-Start-pack Kits). Determine ${ }^{\mathrm{TM}}$ HIV-1/2 kits used were manufactured by Inverse Medical Technical Specialist Laboratory, UK. The fifty (50) controls for this study were recruited among volunteers who were on routine medical check-up at the teaching hospital. These were matched for age with the cases. They were also screened for HIV and pulmonary TB and confirmed negative.

Exclusion criteria: Patients with symptoms of malaria fever, Diabetes Mellitus, patients with intestinal infections which could lead to dysentery, women using contraceptives, patients on corticosteroids therapy, pregnant women and patients with symptoms of jaundice, chronic obstructive pulmonary diseases, cancers and other chronic illnesses were excluded from this study. 
Treatment: After their tuberculosis was diagnosed, patients were commenced on Anti-TB drugs of Directly Observed Treatment-Short course (DOTS) according to National guidelines on treatment of TB and TB and HIV co-infection. ${ }^{9}$ All cases were managed by the attending TB Physicians.

\section{Blood and sputum sample collection}

Five to seven millimeters of venous blood was obtained from the cubital vein of each subject using a sterile needle and syringe into a lithium heparin bottle. The plasma was extracted by centrifugation for 10 minutes at $4000 \mathrm{rpm}$ into a plain bottle and stored at $-20^{\circ} \mathrm{C}$ until the time of analysis for electrolytes and free radicals. The sputum of patients (except those on anti-tuberculosis drugs) and controls were collected into sterile universal bottles for Ziehl-Nelseen staining.

\section{Biochemical analysis}

Estimation of Free Radical: using Thiobarbituric acid reacting method was based on the principle that Trichloroacetic acid (TCA) precipitates protein and thiobabituric acid reacts with Malondialdehyde (MDA) to give a red coloured complex that is read spectrophotometrically at $532 \mathrm{~nm} .{ }^{11}$
Estimation of electrolytes levels: Sodium and Potassium were estimated using Flame emission spectrophotometry method. ${ }^{11}$ Chloride was estimated using Colorimetric: TPTZ [Mercury (II)-2,4,6-tri-(2-pyridyl)s-triazine] method. Bicarbonate was estimated using Back Titration method. ${ }^{12,13}$.

Data management: Data was entered into the computer and analyzed using the SPSS software version 17.0 Validity of data entered was further ensured through double entry of data and random checks. Frequency tables were generated and mean values were calculated.

\section{Results}

Figure I is a pie chart showing the frequency and percentage distribution of the study population. The test groups comprised of three (3) groups; the first group being the new cases and made up of 20 patients (18.18\% of the total population) who were not on drugs. The second group comprising of 20 patients who had been on drugs for $5-6 w e e k s$ (18.18\% of the total population) while the third group were those having co-infection with HIV. They were also made up 20 patients and were not on drugs $(18.18 \%$ of the total population). The control group was of 50 patients $(45.45 \%$ of the total population)

\section{Figure I: $\quad$ Frequency $\&$ percentage distribution of the study}

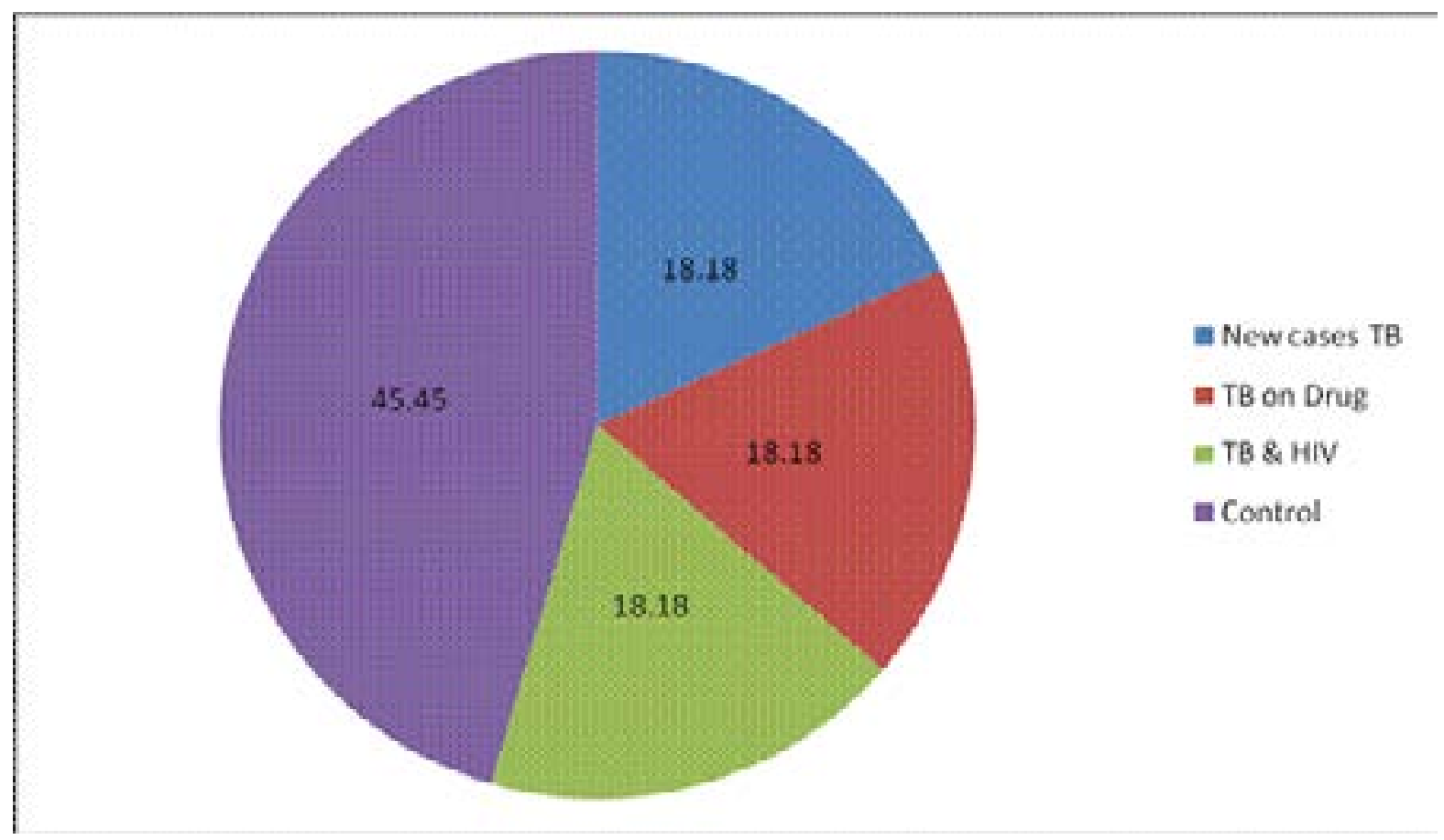


Biochemical parameters: In Table I, The free radicals were significantly lower in control patients when compared with total subject population, new case TB patients, and TB co-infection with $\mathrm{HIV}(0.17 \pm 0.90 \mathrm{Vs}$ $0.25 \pm 0.11,0.27 \pm 0.08,0.30 \pm 1.45 \mu \mathrm{mol} / \mathrm{L} ; \mathrm{P}<0.05)$. However, a slight significantly higher mean value was observed in the controls when compared with TB patients on drugs $(0.18 \pm 0.90 \mathrm{Vs} 0.17 \pm 0.86 \mu \mathrm{mol} / \mathrm{L}$;
$\mathrm{P}<0.05)$. Moreover, the mean value of the free radicals was significantly higher in TB co-infection with HIV when compared with new cases TB patients and TB patients on drugs $(0.30 \pm 1.45$ Vs $0.27 \pm 0.08,0.17 \pm 0.86$ $\mu \mathrm{mol} / \mathrm{L} ; \mathrm{P}<0.05)$. Also, the mean value of the free radicals of new cases TB patients was significantly higher when compared with TB patients on drugs $(0.27 \pm 0.08$ Vs $0.17 \pm 0.86 \mu \mathrm{mol} / \mathrm{L} ; \mathrm{P}<0.05)$, table 5 .

Table I: Comparison between total subject population, control and various TB patients

\begin{tabular}{llcccc}
\hline Patients & $\begin{array}{l}\text { Patients=20 } \\
\text { NCT } \\
\mathrm{M} \pm \mathrm{SD}\end{array}$ & $\begin{array}{c}\text { Controls=50 } \\
\text { TBD } \\
\mathrm{M} \pm \mathrm{SD}\end{array}$ & $\begin{array}{c}\text { t- } \\
\text { value }\end{array}$ & p-value & $\begin{array}{c}\text { Level of } \\
\text { significance }\end{array}$ \\
\hline $\begin{array}{l}\text { Total subject } \\
\text { population Vs control }\end{array}$ & $0.25 \pm 0.11$ & $\mathbf{0 . 1 8} \pm 0.90$ & 4.48 & 0.00 & $\mathrm{P}<0.05$ \\
\hline $\begin{array}{l}\text { New case TB Vs TB } \\
\text { on drug }\end{array}$ & $0.27 \pm 0.08$ & $0.17 \pm 0.86$ & 2.66 & 0.02 & $\mathrm{P}<0.05$ \\
\hline $\begin{array}{l}\text { TB patients on drug } \\
\text { Vs TB patients co- } \\
\text { infection with HIV. }\end{array}$ & $0.17 \pm 0.86$ & $0.30 \pm 1.45$ & 2.63 & 0.12 & $\mathrm{P}<0.05$ \\
\hline $\begin{array}{l}\text { New cases TB subject } \\
\text { Vs TB co-infection } \\
\text { with HIV patients. }\end{array}$ & $0.27 \pm 0.08$ & $0.30 \pm 1.45$ & 3.01 & 0.01 & $\mathrm{P}<0.05$ \\
\hline $\begin{array}{l}\text { TB co-infection with } \\
\text { HIV Vs Control }\end{array}$ & $0.30 \pm 1.45$ & $0.18 \pm 0.90$ & 4.59 & 0.00 & $\mathrm{P}<0.05$ \\
\hline $\begin{array}{l}\text { New cases TB } \\
\text { patients Vs TB co- } \\
\text { infection with HIV }\end{array}$ & $0.27 \pm 0.08$ & $0.30 \pm 1.45$ & 3.01 & 0.01 & $\mathrm{P}<0.05$ \\
\hline $\begin{array}{l}\text { TB patients on drug } \\
\text { Vs TB patients co- } \\
\text { infection with HIV }\end{array}$ & $0.17 \pm 0.86$ & $0.30 \pm 1.45$ & 2.63 & 0.12 & $\mathrm{P}<0.05$ \\
\hline
\end{tabular}

Table II showed the Pearson's correlation of TB patients co-infected with HIV. It showed a positive correlation between sodium and chloride $(\mathrm{r}=0.979, \mathrm{P}<0.01)$, sodium and free radicals $(\mathrm{r}=0.767, \mathrm{P}<0.01)$, and chlo- ride and free radicals $(\mathrm{r}=0.785, \mathrm{P}<0.01)$. There was also an inverse correlation between potassium and chloride $(\mathrm{r}=0.763, \mathrm{P}<0.01)$, potassium and sodium $(\mathrm{r}=0.793$, $\mathrm{P}<0.01)$ and potassium and free radicals $(\mathrm{r}=0.478$, $\mathrm{P}<0.05)$.

Table 2: Pearson's correlation table of tuberculosis co-infection with HIV patients.

\begin{tabular}{|c|c|c|c|c|c|}
\hline Variable & $\mathrm{Na}^{+}(\mathrm{mmol} / \mathrm{L})$ & $\mathrm{K}^{+}(\mathrm{mmol} / \mathrm{L})$ & $\mathrm{Cl}^{-}(\mathrm{mmol} / \mathrm{L})$ & $\begin{array}{r}\mathrm{HCO}^{-} \\
(\mathrm{mmol} / \mathrm{L})\end{array}$ & $\begin{array}{r}\text { Free radicals } \\
(\mu \mathrm{mol} / \mathrm{L})\end{array}$ \\
\hline $\mathrm{Na}^{+}(\mathrm{mmol} / \mathrm{L})$ & 1 & $-.793 * *$ & $.979 *$ & -.109 & $.767 * *$ \\
\hline $\mathrm{K}^{+}(\mathrm{mmol} / \mathrm{L})$ & $-.793 * *$ & 1 & $-.763 * *$ & .115 & $-.428 *$ \\
\hline $\mathrm{Cl}^{-}(\mathrm{mmol} / \mathrm{L})$ & $.979 * *$ & $-.763 * *$ & 1 & -.306 & $.785 * *$ \\
\hline $\mathrm{HCO}^{-}(\mathrm{mmol} / \mathrm{L})$ & -.109 & .115 & -.306 & 1 & -.220 \\
\hline $\begin{array}{ll}\text { Free } & \text { radicals } \\
(\mu \mathrm{mol} / \mathrm{L}) & \end{array}$ & $.767 * *$ & $-.478 * *$ & $.785^{*}$ & -.220 & 1 \\
\hline
\end{tabular}

\section{Discussion:}

In this study, mean values of MDA was significantly higher in various TB cases when compared with controls. This supports another study in which higher values of MDA level were found in patients with active TB compared to healthy controls and the difference was statistically significant with $\mathrm{P}=0.001 .{ }^{14}$ In another re- lated study, the concentration of MDA was higher in cases with active TB and TB / HIV cases on treatment than in the control groups. ${ }^{15}$ In yet another study, serum MDA concentration as a measure of lipid peroxidation reflecting the degree of oxidative stress was reported to be significantly higher in patients with tuberculosis than in healthy subjects. ${ }^{16}$ 
The significantly higher level of free radicals found in new case pulmonary tuberculosis patients, and TB co-infection with HIV can be attributed to the facts that mycobacterium induces ROS and RNI by activating phagocytes ${ }^{14-16}$ which promote tissue injury and inflammation. This further contributes to immunosuppression in HIV infected patients. ${ }^{17}$ The bearing influence on ROS and RNI1 compared to controls could be as a result of possible loss of electrolytes during excessive sweating associated with TB, diarrhea and vomiting which are common with HIV and co-infection with TB and HIV disease. In HIV/AIDS infection, there is the killing of cells by virus, high grade pyrexia (causing the destruction of cells) and therefore leading to development of lung fibrosis which may be a long term sequel of pulmonary tuberculosis. ${ }^{18}$

The observed lower significance in TB patients on drug than new case TB patients and TB co-infections with HIV could therefore be the effect of Rifampicin on the phagocytic cells. ${ }^{19}$ The elevated electrolytes levels (most especially sodium and chloride) suggests the importance of carrying out levels of MDA and electrolytes during management of active TB cases. This is to prevent occurrences of water and electrolyte imbalance and the possible damaging effects of free radicals. The inability of this study to do a Polymerase Chain Reaction (PCR) or culture to differentiate between typical and atypical Mycobacteria due to resource constraints could be regarded as a limitation to this study. This could have given a differential diagnosis with the likelihood of presenting with similar symptoms. This is however not a main focus of this research. In conclusion, reduced serum MDA levels in tuberculosis patients on drugs suggest a reduction in the levels of free radical injury once treatment is commenced. Therefore serum free radical may be an index of monitoring response to treatment in tuberculosis management. The use of serum MDA level at regular intervals is hereby recommended as a prognostic/monitoring index in patients with tuberculosis treatment.

\section{Acknowledgement:}

The authors are grateful to the Medical Directors of participating hospitals, TB program Director, the Laboratory Department of LAUTECH, College of Health Sciences as well as all patients who participated in the study.

\section{Conflict of Interest:}

None among authors and institutions relevant to this manuscript

\section{Funding:}

No external funding was received towards the conduct of this research.

\section{References}

1. World Health Organization (WHO). Tuberculosis Fact sheet 2006; No 104 - Global and regional incidence; October 2013.

2. Centers for Disease Control and Prevention. Plan to combat extensively drug-resistant tuberculosis: recommendations of the Federal Tuberculosis Task Force. MMWR Recomm Rep, 2009; 58 (RR-3):1-43.

3. Reddy YN, Murthy SV, Krishna DR, Prabhakar MC. Role of free radicals and antioxidants in TB patients, Indian Journal of Tuberc. 2004;51:213-218

4. Cem EH, Yusuf TR, Mustafa Cekmen. Serum levels of TNF-a , sIL-2R, IL-6, and IL-8 are increased and associated with elevated lipid peroxidation in patients with Behçet's disease. Mediators of Inflammation. 2002;11:87-93.

5. Rook GA, Seah G, Ustianowski AM Tuberculosis immunology and vaccination. Eur Respir Journal, 2001; 17:537-557.

6. Dong-Ho Shin, Sabrina S. Martinez, M, Parsons, DT, Jayaweera AC, and Marianna KB Relationship of Oxidative Stress with HIV Disease Progression in HIV/ HCV Co-infected and HIV Mono-infected Adults in Miami. Intl J Biosci Biochem Bioinforma. 2012; 2(3): 217223.

7. Wild I, Seaman T, Hoal EG, Benade AJ, Van HPD. Total antioxidant levels are low during active $\mathrm{TB}$ and rise with anti-tuberculosis therapy .IUBMB Life, 2004; 56(2):101 PubMed -6

8. Corbett EL, Watt CJ, Walker N. The growing burden of tuberculosis: global trends and interactions with the HIV epidemic. Arch Intern Med, 2003; 163:1009-1021 PubMed.

9. National Population Commission (NPC). Nigeria Demographic and Health Survey 2006. Preliminary report of the National Population Commission. Federal Republic of Nigeria, Abuja, Nigeria 2006

10. National Agency for the Control of HIV/AIDS (NACA) 2010. Prevalence of HIV among Tuberculosis and HIV co-infected clients. NACA Abuja Nigeria 2010. 
11. Yagi K. A simple fluorometric assay for lipoperoxide in blood plasma. Biochem Med, 1976; 15:212-6 11.

12. Bhagat CJ, Garcia-Webb P, Fletcher E, Beilby JP. Calculated vs measured plasma osmolalities revisited. Clinical Chemistry, 1984; 30(10):1703 PubMed -5 12.

13. Skeggs LT, Hochstrasser HC. Colometric method of chloride estimation. Clin.Chem, 1964; 10:918-920 PubMed

14. Dhia AT and Imad AJT.Antioxidant Status, C - reactive protein and Iron Status in Patients with Pulmonary Tuberculosis. Sultan Qaboos Univ. Med J. 2010;10(3): 361 PubMed -369

15. Van Doom HR, Claas EC, Templeton KE, van der Zanden AG, te Koppele vije A, de long MD,dankert J, Kijper EJ. Detection of a point mutation associated with high level INH resistance in MTB by using real time technology PCR with 3 minor groove binder DNA probe. J Clin.Microbiology, 2003;41:4630-35 PubMed , 16. Madebo T, Lindtjørn B, Aukrust P and Berge RK. Circulating antioxidants and lipid peroxidation products in untreated tuberculosis patients in Ethiopia. Am J Clin Nutr, 2003;78 (1): 117-122

17. Muller F, Svardal AM, Nordoy I, Berge RK, Aukrust P, Froland SS. Virological and immunological effects of antioxidant treatment in patients with HIV infection. Eur J Clin Invest, 2000; 30: 905-914 PubMed

18. Jack CI, Jackson MJ. Hind CR. Circulating markers of free radical activity in patients with pulmonary tuberculosis. Tuber Lung Dis, 2004;75 : 132-137 PubMed. 19. Yael YI, Azoulay-Alfaguter EB, Rifampin Inhibits Prostaglandin E2 Production and Arachidonic Acid Release in Human Alveolar Epithelial Cells Antimicrobials Agents Chemother. 2007; 51(12): 4225-4230. 